\title{
Regulating physical and chemical properties of leached chernozems in the forest-steppe of the Southern Urals
}

\author{
Rustiam Kiraev, Iahia Kaipov*, and Anvar Shakirzianov \\ Ufa Federal Research Center of the Russian Academy of Sciences, Bashkir Research Institute of \\ Agriculture, Ufa, Russia
}

\begin{abstract}
The objective of this study was to identify the effect of long-term use of lime, mineral and organic fertilizers on the physico-chemical properties of leached chernozem in the forest-steppe of the Southern Urals. Field experiments were conducted in the instructional farm of the Bashkir Agricultural Research Institute. The terrain is flat. Average annual precipitation varies from 389 to $500 \mathrm{~mm}$. The sum of active temperatures reaches $2180-2230$ ${ }^{0} \mathrm{C}$. The effect of experiment factors was studied in six-field grain-fallow and grain-grass crop rotation fields. The lime rates were calculated according to the total hydrolytic acidity of the soil. The dosage of organic and mineral fertilizers was determined to get the planned yields of crops in the given crop rotation. After liming, the reaction of the soil medium in the arable layer reaches optimal values for crops being $\mathrm{pH}$ 5.8-6.0. The amount of exchangeable bases increases from 38-41 to 43-45 mg-eq/100 $\mathrm{g}$ of soil. As a result of the complex application of liming, organic and mineral fertilizers, the physico-chemical properties of leached chernozem get close to the optimal parameters for field crop cultivation.
\end{abstract}

\section{Introduction}

The integrated application of cultivation practices in field crop rotations in the Southern Urals significantly changes the physical and chemical properties of the soil. These properties determine the level of effective soil fertility.

The soil cover in the Southern Urals is mainly chernozems. The arable lands of this region are dominated by leached chernozems, which occupy a fifth of the total area [1].

Previous research made a detailed analysis of the acidity dynamics for different soil types, revealed the interrelationship of soil acidification with the loss of bases from the arable layer, estimated the soil calcium balance in the Russian Federation (RF) [2]. It was found that the root zone acidification results from constant calcium migration with infiltration waters and biological processes with the release of "acidic" products. On the whole, $48 \%$ of soils in the Russian Federation are characterized by very low (less than $5 \mathrm{mg}$-eq./100 g), low (5-20 mg-eq./100 g) and average $(20-60 \mathrm{mg} / \mathrm{eq} . / 100 \mathrm{~g})$ calcium content. Most medium-calcium-rich soils are in the Ural, East Siberian and Far Eastern regions (18-41 \% of the studied areas). Much uncertainty

\footnotetext{
*Corresponding author: sci_secr_bniish@bk.ru
} 
still exists about providing calcium availability. Agrochemical methods, mainly liming, can solve it.

I.G. Asylbaiev and I.K. Khabirov (2016) claim that there is a need to conduct further agrochemical experiments to explore the efficacy of alkali (calcium) and alkaline earth elements in the composition of mineral fertilizers for different soil and climatic conditions [3].

There is evidence that mineral fertilizers, especially ammonia forms, increase the solubility of soil carbonates and result in the downward movement of released calcium beyond the root zone. Then calcium combined with anions of strong acids migrates down to ground water [4]. It has been demonstrated that one kilogram of nitrogen in mineral fertilizers leaches an average of $3 \mathrm{~kg}$ of calcium carbonate. Ammonium sulfate nitrogen reduces up to $6 \mathrm{~kg}$ of this valuable cation in the soil [5]. As a result of the lower calcium content, the soil-absorbing complex (SAC) is depleted by bases, the proportion of hydrogen and aluminium cations rises, leading to higher acidity [6]. The multi-year analysis of the soil solution acidity at the prolonged application of mineral fertilizers conducted from 1968 to the present time showed an increase in the acidity of meadow-chernozem soils in the Amur region by $12-14 \%$ [7]. Higher acidity of leached chernozems resulting from longterm use of mineral fertilizers has been reported for the Western Fore-Caucasus [8]. A search of the academic literature on regulating the physical and chemical properties of soils in the Russian Federation reveals a deep concern on the deteriorated cationic composition of the SAC with subsequent acidification of the soil medium in different soils, including chernozems. Research in this area is insufficient and requires field experiments lasting at least 20 years. Considering the existing studies, the present paper aimed to conduct longterm field experiments on the physical and chemical properties of leached chernozems when using liming and fertilizers in crop rotations.

\section{Materials and methods}

Field experiments were carried out in the instructional farm of the Bashkir State Agrarian University, located in the forest-steppe of the Southern Urals. The experiments had five treatments in three replications in randomized plot design. The terrain of the experimental field is flat; the soil is medium-thick heavy loamy leached chernozem. The climate in the area of the field experiments is warm and moderately humid. The average annual precipitation is $389-500 \mathrm{~mm} .76 \%$ of the rainfall occurs during the growing season. The average annual air temperature is $2.3^{\circ} \mathrm{C}$. The sum of active temperatures is $2180-2230{ }^{\circ} \mathrm{C}$.

The effect of experiment factors was studied in two experimental six-field crop rotation fields. The first grain-fallow field rotated fallow, winter rye, spring wheat, corn, spring wheat, barley. The second grain-grass field had the rotation set of fallow, winter rye, spring wheat with interplanted grass, first-year rotation grass, second-year rotation grass-, spring wheat.

Fertilizers in crop rotation were used according to the following scheme:

1. Control treatment without fertilizers and lime

2. NPK * - fertilizers, without lime

3. $\mathrm{NPK}+\mathrm{Ca}^{* *}, 4 \mathrm{t} / \mathrm{ha}$ lime in fallow field

4. Manure without NPK, $40 \mathrm{t} / \mathrm{ha}$ in a fallow field

5. Manure + NPK, without lime

6. Manure $+\mathrm{NPK}+\mathrm{Ca}$

7. Green manure, $25 \mathrm{t} / \mathrm{ha}$ in a fallow field, without NPK

8. Green manure + NPK,

9. Green manure $+\mathrm{NPK}+\mathrm{Ca}$.

* NPK stands for nitrogen, phosphorus and potash mineral fertilizers

** Ca stands for lime $\left(85 \% \mathrm{CaCO}_{3}\right)$ 
Fertilizer rates in experiments were used given the planned yield of cultivated crops. They were as follows: $\mathrm{N}_{71} \mathrm{P}_{89} \mathrm{~K}_{54}$, to get $40 \mathrm{c} /$ ha of winter rye, $\mathrm{N}_{68} \mathrm{P}_{90} \mathrm{~K}_{36}$ for spring wheat (35 c/ha), $\mathrm{N}_{77} \mathrm{P}_{91} \mathrm{~K}_{54}$ for corn (500 c of green mass), $\mathrm{N}_{53}, \mathrm{P}_{70} \mathrm{~K}_{28}$ for barley (35 c/ha), $\mathrm{N}_{58} \mathrm{P}_{57} \mathrm{~K}_{56}$ for perennial grasses (50 c/ha of hay ). As a lime ameliorant, lime tuff with $85 \%$ $\mathrm{Ca} \mathrm{CO}_{3}$ was used. The manure composition in per cent was N-0.46; P-0.30; K-0.50; Ca0.80 . Used types of mineral fertilizers: urea, superphosphate, potassium chloride. Agrochemical indicators of the arable layer in leached chernozem: humus content $9.0 \%$, gross nitrogen- $0.46 \%$, phosphorus- $0.17 \%$, potassium- $1.40 \%$; the amount of absorbed bases - 39.1 mg-eq per $100 \mathrm{~g}$ of soil, $\mathrm{pH}_{\mathrm{KCl}}-5.3$.

Lime and fertilizers were applied during primary cultivation. Scientific research and analytical work were carried out using methods generally accepted in scientific institutions. Solvent analysis was made according to the method developed by the Central Research Institute of Agrochemical Maintenance (CRIAM), Russian State standard GOST 26483-85. Hydrolytic acidity was examined by the Kappen method modified by the CRIAM, Russian State standard GOST 26212-91. Exchange calcium and exchange magnesium were explored by the CRIAM methods, Russian State standard GOST 26487-85. The sum of absorbed bases was investigated according to the Kappen method, Russian State standard GOST 27821-88.

\section{Results and discussion}

Liming in the experiment had a neutralizing effect on the medium reaction of the arable layer in leached chernozem (Table 1). Treatment without lime (in the table - the option "Without fertilizers") had a mid acid medium reaction from $\mathrm{pH} 4.8$ to $\mathrm{pH} 5.1$ during all the experiment periods. Treatment with mineral fertilizers and manure (NPK + manure) had a more acidic reaction of the medium with $\mathrm{pH}$ values of 4.5-4.8. Treatments with the separate lime application based on total hydrolytic acidity and liming with manure and mineral fertilizers had the optimal soil medium reaction in the arable layer of $\mathrm{pH} 6.0$ and $\mathrm{pH} 5.8$, respectively, in the first period of the experiment. The first series of experiments demonstrated that the soil of the experimental field, leached chernozem, is acidified during crop cultivation practices from a medium to a strong degree and requires soil solution reaction neutralization by liming.

Table 1. Dynamics of changes in $\mathrm{pH}$ indicators in the arable layer of leached chernozem under the impact of fertilizers and liming in the crop rotation.

\begin{tabular}{|l|c|c|c|c|c|c|}
\hline \multirow{2}{*}{ Treatment } & \multicolumn{6}{c|}{ Liming reference periods } \\
\cline { 2 - 7 } & First & Fourth & Seventh & Eighth & Ninth & \multirow{2}{*}{ Tenth } \\
\hline Without fertilizers & 4.8 & 4.9 & 4.8 & 4.9 & 5.0 & 5.1 \\
\hline Lime & 6.0 & 5.8 & 5.8 & 5.5 & 5.2 & 5.3 \\
\hline NPK + Manure & 4.5 & 4.7 & 4.8 & 4.8 & 4.6 & 4.2 \\
\hline NPK + Manure+Lime & 5.8 & 5.7 & 5.4 & 5.3 & 4.9 & 4.7 \\
\hline HCP05 & 0.3 & 0.2 & 0.3 & 0.3 & 0.2 & 0.2 \\
\hline
\end{tabular}

* year of liming

As mentioned above, when lime was applied together with fertilizers, the $\mathrm{pH}$ value was 0.2 units lower relative to the sample with only liming. This value remained significantly lower in liming with fertilizers in subsequent periods than with the separate use of ameliorant (the corresponding $\mathrm{pH}$ values of 4.7 and 5.3 in the 10th period). This is due to the acidifying effect of mineral fertilizers. 
The conducted research showed a need for lime reapplication eight years after introducing it without fertilizers when the $\mathrm{pH}$ decreases to 5.2 and six-seven years after using organic and mineral fertilizers. Thus, the application of mineral fertilizers requires repeated liming 1-2 years earlier due to their acidifying effect.

The use of lime, manure and mineral fertilizers in the experimental crop rotation also influenced the change in the hydrolytic acidity (HAC) of the soil. When applying lime without fertilizers, the soil was characterized by the lowest values of hydrolytic acidity (Table 2). Values in this treatment were 5.3 in the first year, 4.7 in the fourth year, which is respectively 1.7 and 2.2 times less than the option without fertilizers and lime.

Table 2. The effect of fertilizers and liming in crop rotation on the hydrolytic acidity of the arable layer of leached chernozem, mg-eq $/ 100 \mathrm{~g}$ of soil

\begin{tabular}{|c|c|c|c|c|c|}
\hline \multirow{2}{*}{ Treatment } & \multicolumn{5}{|c|}{ Liming reference periods } \\
\cline { 2 - 6 } & First & Fourth & Seventh & Eighth & Ninth \\
\hline Without fertilizers & 8.9 & 10.3 & 8.5 & 8.0 & 8.6 \\
\hline Lime & 5.3 & 4.7 & 7.6 & 7.0 & 7.4 \\
\hline NPK + Manure & 11.6 & 13.2 & 13.1 & 12.9 & 13.1 \\
\hline $\begin{array}{c}\text { NPK+ } \\
\text { Manure+Lime }\end{array}$ & 7.0 & 8.6 & 10.2 & 10.2 & 9.8 \\
\hline HCP 05 & 0.2 & 0.3 & 0.2 & 0.3 & 0.2 \\
\hline
\end{tabular}

By the seventh year from the beginning of liming, the hydrolytic acidity increased significantly, approaching the control treatment without fertilizers and lime, with the corresponding values of 7.6 and $8.5 \mathrm{mg}$-eq. $/ 100 \mathrm{~g}$ of soil. In the subsequent liming reference periods (the 8 th and 9 th periods), the increased values of hydrolytic acidity close to the unlimed background were preserved. Long-term use of fertilizers (without liming) led to higher hydrolytic acidity of 12-13 mg-eq./100 $\mathrm{g}$ of soil.

Liming and long-term use of fertilizers (treatment: lime+manure+NPK) contributed to a decrease in hydrolytic acidity to values of $7.0 \mathrm{mg}$-eq $/ 100 \mathrm{~g}$ in the $1 \mathrm{st}$ period and $8.6 \mathrm{mg}$ eq $/ 100 \mathrm{~g}$ in the 4 th period. By the 7 th period, the indicator increases again, taking the value of 10.2, which is significantly higher than options without fertilizers and lime use. Consequently, there is a need for repeated soil liming to reduce hydrolytic acidity at this reference time. These findings suggest that the timing of repeated liming, determined by the $\mathrm{pH}$ and hydrolytic acidity, coincide.

According to the theory of KK, Gedroyts (1953), the composition of the soil absorbing complex (SAC) affects such important soil properties as buffering, the cation release for the root nutrition due to exchange reactions with the soil solution and the root system of plants. Exchange cations regulate soil-forming processes that affect soil fertility. Considering the provisions mentioned above, the present study experimentally identified patterns of changes in the SAC composition explored at soil liming in crop rotation over nine years.

The amounts of exchange bases in treatment without fertilizers did not change significantly in the crop rotation for nine years, being 37.2-41.3 mg-eq per $100 \mathrm{~g}$ of soil (Table 3).

Table 3. Change in the total exchangeable bases in the arable layer of leached chernozem under the impact of fertilizers and liming, $\mathrm{mg}$-eq $/ 100 \mathrm{~g}$ of soil.

\begin{tabular}{|l|c|c|c|c|c|}
\hline \multirow{2}{*}{ Treatment } & \multicolumn{5}{|c|}{ Liming reference periods } \\
\cline { 2 - 6 } & First & Fourth & Seventh & Eighth & Ninth \\
\hline $\begin{array}{l}\text { Without } \\
\text { fertilizers }\end{array}$ & 38.7 & 37.2 & 41.3 & 41.2 & 40.8 \\
\hline Lime & 43.3 & 44.3 & 42.4 & 42.4 & 41.6 \\
\hline
\end{tabular}




\begin{tabular}{|l|c|c|c|c|c|}
\hline NPK + Manure & 35.6 & 36.9 & 39.8 & 41.0 & 40.4 \\
\hline $\begin{array}{l}\text { NPK+Manure+ } \\
\text { Lime }\end{array}$ & 43.9 & 40.6 & 45.5 & 43.0 & 42.6 \\
\hline $\mathrm{HCP}_{05}$ & 0.8 & 0.9 & 0.8 & 0.9 & 0.9 \\
\hline
\end{tabular}

When lime was applied separately, in the first years after its application, the amount of exchangeable bases significantly increased to the values of $43-44 \mathrm{mg}$-eq/100 g. However, already in the 9th year, the amount of exchangeable bases in the soil of the limed treatment decreased to $41.6 \mathrm{mg}$-eq / $100 \mathrm{~g}$, almost comparing with the version without fertilizers. These results accord with findings at the Tatar Research Institute of Agrochemistry and Soil Science. A. Kh. Iapparov et al. also reported increased exchangeable bases when using phosphorites and glauconites on leached chernozem 8]. The use of mineral fertilizers and manure (treatment "NPK + manure") at the beginning of the experiment led to a decrease in the amount of exchangeable bases in the soil to $35-39 \mathrm{mg}$-eq/100 $\mathrm{g}$ from the $1 \mathrm{st}$ to the 7 th period while in control without fertilizers they were $38-41 \mathrm{mg}-\mathrm{eq} / 100 \mathrm{~g}$. Liming with fertilizers replenished exchangeable bases to the level observed at the treatment, with the separate lime application being 43-44 mg-eq/100 $\mathrm{g}$ from the $1 \mathrm{st}$ to the 4 th period (years of lime application). There was extended reproduction from the 7th period onwards with indicators of $43.0-45.5 \mathrm{mg}$-eq/100 g. It is due to a mutual strengthening of two factors-lime and organic fertilizers (manure), in replenishing the sum of the exchangeable bases in the soil.

During the periods of repeated liming (starting from the 10th year from the beginning of the first liming), the reaction of the soil medium (solution) changed slightly. It was $\mathrm{pH}$ 4.9-5.2 for treatments without fertilizers and liming. These indicators correspond to the characteristics of medium-acid and strongly acid soils [10]. During the initial 1-9 periods, the untreated soil had almost the same acidity values (Table 3 ). Thus, under conditions without liming and fertilizers, the reaction of the leached chernozem medium does not change much for a long time, ranging from medium to slightly acid.

Table 4. The effect of fertilizers and liming on the reaction of the medium (pH) of the arable layer of leached chernozem during repeated liming in the crop rotation.

\begin{tabular}{|l|c|c|c|c|c|}
\hline \multirow{2}{*}{ Treatment } & \multicolumn{5}{|c|}{ Reference periods of repeated liming } \\
\cline { 2 - 6 } & $\begin{array}{c}\text { Tenth } \\
\text { (1st year) }\end{array}$ & Fifteenth & $\begin{array}{c}\text { Sixteenth } \\
\text { (7th year) }\end{array}$ & $\begin{array}{c}\text { Seventeent } \\
\mathrm{h}\end{array}$ & Eighteenth \\
\hline Without fertilizers & 5.0 & 5.1 & 4.9 & 5.2 & 5.0 \\
\hline Lime & 6.1 & 6.0 & 5.8 & 5.6 & 5.5 \\
\hline NPK + Manure & 4.4 & 4.7 & 4.6 & 4.8 & 4.7 \\
\hline $\begin{array}{l}\text { NPK + } \\
\text { Manure+Lime }\end{array}$ & 6.0 & 5.8 & 5.5 & 5.6 & 5.3 \\
\hline HCP05 & 0.2 & 0.3 & 0.2 & 0.3 & 0.3 \\
\hline
\end{tabular}

After repeated liming, the $\mathrm{pH}$ value of the soil in the treatment of separate lime application rose to the level of 6.1 units (Table 4, see column "10th period"), whereas before repeated lime application, this indicator was $\mathrm{pH} 5.3$ (Table 1). A long time after repeated liming, from the 10th to the 18th periods, the reaction of the soil medium in the treatment of pure (independent) lime application was within the optimal range for most field crops - above $\mathrm{pH}$ 5.3. This means that the aftereffect of repeated liming is more than eight years. Thus, the neutralizing effect of lime remains high at the repeated application as well. In the treatment of repeated liming with fertilizers, the aftereffect of lime already ends in the 18th period, when the $\mathrm{pH}$ value decreases to 5.3, more than one year earlier than in pure liming. Comparing the aftereffects of two liming treatments shows that the need for repeated liming during each cycle are approximately the 
same. For seven years from the beginning of the repeated liming period (since 1992), the reaction of the soil medium in the treatment with fertilizers (without liming) remained acid from strong to medium ( $\mathrm{pH} 4.4-4.8$ ), almost as in the period of initial liming (Table 4). Consequently, the intensive use of fertilizers on chernozem, traditionally unlimed, leads to significant acidification and requires liming.

Table 5. The effect of fertilizers and repeated liming on the hydrolytic acidity of the arable layer of leached chernozem, mg-eq $/ 100 \mathrm{~g}$ of soil.

\begin{tabular}{|l|c|c|c|c|c|}
\hline \multirow{2}{*}{ Treatment } & \multicolumn{5}{|c|}{ Reference periods of repeated liming } \\
\cline { 2 - 6 } & Tenth & Fifteenth & Sixteenth & Seventeenth & Eighteenth \\
\hline Without fertilizers & 7.8 & 7.7 & 8.1 & 8.3 & 7.9 \\
\hline Lime & 5.0 & 4.8 & 5.0 & 5.3 & 5.6 \\
\hline NPC + Manure & 12.9 & 13.1 & 12.8 & 13.0 & 11.8 \\
\hline $\begin{array}{l}\text { NPK + } \\
\text { Manure+Lime }\end{array}$ & 6.1 & 6.2 & 6.5 & 7.8 & 7.3 \\
\hline $\mathrm{HCP}_{05}$ & 0.4 & 0.5 & 0.4 & 0.5 & 0.5 \\
\hline
\end{tabular}

During repeated liming, the hydrolytic acidity of the soil decreased significantly compared to the indicators during the first liming. In the first periods after repeated liming, from the 10th to the 16th, the hydrolytic acidity in the pure liming treatment was steadily within the range of 4.8-5.0 mg-eq./100 g. The values started to rise to 5.3-5.6 units from the 17 th period (Table 5). The hydrolytic acidity levels are 1.7-2.3 units less than during the aftereffect of the first liming (Table 2). A more pronounced neutralizing effect of lime during its repeated application with mineral fertilizers and manure. Thus, from the 10th to the 16th periods of active interaction of lime with the soil, the hydrolytic acidity did not exceed 6.1-6.5 units, whereas these indicators were higher, being 7.0-10.2 at the first liming (Table 2).

Reduced hydrolytic acidity after repeated liming with fertilizers lasted until the 16 th period, that is, for five years (Table 5). This is two years less than the aftereffect at the first liming. In the 17 th period, the hydrolytic acidity increases to $7.8 \mathrm{mg}$-eq/100 g, with a relative excess of $28 \%$ from the initial level during repeated liming, which indicates the need for a new liming. This suggests that the need for repeated liming at the treatment with fertilizers occurs 1-2 years earlier than during the first liming.

The average data for the experimental crop rotation show that the soil was acidified to the greatest extent in the treatments with mineral fertilizers (NPK), joint application of mineral fertilizers and green manure, joint application of mineral fertilizers and manure (Table 6). The soil acidity in these treatments was $\mathrm{pH}$ 5.15-5.23; HAC 5.9-6.2 mg-eq./100 $\mathrm{g}$; with $\mathrm{pH} 5.30$ and HAC 5.7 in control. The differences between the listed treatments are within the least significant difference (LSD 05 ) and tend to change under experimental factors. However, a change in the values by only a few tenths of the acidity units entails significant changes in the analyzed soil properties. Therefore, insignificant differences are critical in describing the physical and chemical properties of the soil in terms of statistical processing.

Table 6. The effect of lime and fertilizers on the physico-chemical properties of leached chernozem (average per crop rotation).

\begin{tabular}{|l|c|c|c|c|c|}
\hline \multirow{2}{*}{ Treatment } & \multirow{2}{*}{$\mathrm{pH}$} & \multicolumn{3}{|c|}{$\mathrm{Mg}$-eq. / $100 \mathrm{~g}$} & \multirow{2}{*}{$\mathrm{V}, \%$ \%* } \\
\cline { 3 - 5 } & & $\mathrm{HAC} *$ & $\mathrm{Ca}^{++}$ & $\mathrm{Ca}^{++}+\mathrm{Mg}^{++}$ & \\
\hline $\begin{array}{l}\text { Control (without fertilizers } \\
\text { and lime) }\end{array}$ & 5.30 & 5.7 & 31.2 & 38.0 & 86.9 \\
\hline NPK & 5.15 & 6.2 & 31.0 & 37.7 & 85.8 \\
\hline
\end{tabular}




\begin{tabular}{|l|c|c|c|c|c|}
\hline $\begin{array}{l}\text { NPK }+ \\
\text { Lime }\end{array}$ & 5.70 & 5.1 & 32.4 & 39.5 & 88.6 \\
\hline Manure & 5.40 & 5.6 & 32.0 & 38.9 & 87.4 \\
\hline $\begin{array}{l}\text { NPK+ } \\
\text { Manure }\end{array}$ & 5.23 & 5.9 & 31.5 & 38.4 & 86.7 \\
\hline $\begin{array}{l}\text { NPK }+ \\
\text { Manure+ } \\
\text { Lime }\end{array}$ & 5.80 & 5.0 & 33.3 & 40.6 & 89.0 \\
\hline Green manure & 5.37 & 5.6 & 31.6 & 38.5 & 87.3 \\
\hline $\begin{array}{l}\text { NPK + Green manure } \\
\text { NPK + Green manure + } \\
\text { Lime }\end{array}$ & 5.16 & 6.0 & 31.1 & 37.9 & 86.3 \\
\hline HCP $_{05}$ & 0.24 & 0.36 & 0.96 & 1.24 & 88.7 \\
\hline
\end{tabular}

$* \mathrm{H}_{\mathrm{g}}$ - hydrolytic acidity of the soil

$* * \mathrm{~V}, \%$ - the degree of base saturation

The acidity of the soil medium in the above three treatments exceed the limit of the optimal value for leached chernozems, which is $\mathrm{pH} 5.3$ [11]. Findings of the present study on changes in soil acidity in treatments with mineral fertilizers indicate that the latter has a dominant effect on increasing acidity. Additional application of manure and green manure has an insufficient neutralizing effect. The best soil acidity was when lime was used with mineral fertilizers and manure or mineral fertilizers, with $\mathrm{pH}$ values of 5.8-5.7 and HAC 5.0-5.1 mg-eq./100 g. Similar results were provided by treatments with manure and green manure, with $\mathrm{pH}$ values of 5.40 and 5.37. This indicates a significant potential of the above organic fertilizers in neutralizing soil acidity. The above treatments ameliorated soil acidity and improved the cationic composition of the SAC. There was a slight increase in the amount of absorbed bases to 38.5-40.6 mg-eq./100 g, the degree of soil saturation with bases to $87.3-89.0 \%$ with values in the control of 38.0 units and $86.9 \%$ (Table 6). However, the achieved indicators still lag behind the optimal values of $46-57 \mathrm{mg} / 100 \mathrm{~g}$ and $90 \%$ for leached chernozems [11].

In contrast to the treatments with liming, the option without fertilizers and lime had more stable physico-chemical properties of the soil during the crop rotation. There was weak acidification of the soil solution with a $\mathrm{pH}$ of 5.34 to 5.28 . The base saturation remained almost unchanged, with values of 86.9 at the beginning of the observation and $86.8 \mathrm{mg}-\mathrm{eq} / 100 \mathrm{~g}$ at the end. There were no significant changes in hydrolytic acidity. These results indicate a relatively stable acidity and the degree of base saturation in the absence of an acidifying factor - fertilizers.

The exchangeable calcium in the SAC under the influence of fertilizers and lime is of special interest. The use of mineral fertilizers in the experiment did not result in a change in the content of the exchangeable $\mathrm{Ca}^{++}$in the soil during the crop rotation. Thus, the treatment with mineral fertilizers (NPK) had the average content of exchangeable calcium in the SAC of the arable soil layer of $31.0 \mathrm{mg}$-eq/100 g, while it was $31.2 \mathrm{mg}$ eq/100 $\mathrm{g}$ in control (Table 6).

The introduction of lime separately and with mineral and organic fertilizers contributed to a noticeable increase in the exchangeable calcium in the SAC. Thus, in the treatment "NPK+lime", the content of the exchangeable $\mathrm{Ca}^{++}$was 32.4 units, which is 1.2 units $(2 \%)$ more than in control without liming. With the joint application of lime, NPK and manure, the content of exchangeable calcium increased by a higher value, reaching $33.3 \mathrm{mg}-\mathrm{eq} / 100 \mathrm{~g}$ of soil. The amount of exchangeable $\mathrm{Ca}^{++}$increased by almost the same amount when amelioration was applied to mineral fertilizers and green manure. Such a positive effect of green manure on the content of exchangeable calcium in the soil 
is an important justification for replacing technologically expensive manure with a cheaper green manure fertilizer.

\section{Conclusion}

During the experimental crop rotation, the soil of the arable layer in conditions without liming acquires a medium acid reaction with indicators from $\mathrm{pH} 4.8$ to $\mathrm{pH} 5.1$. The treatment with mineral fertilizers and manure (NPK + manure) brings in even more acid with $\mathrm{pH}$ values $4.5-4.8$. Liming by total hydrolytic acidity brings the reaction of the soil medium to optimal values for crops. It is $\mathrm{pH} 6.0$ at the separate application of lime and pH 5.8 at liming with manure and mineral fertilizers. The need for repeated liming of leached chernozem arises after eight years when the $\mathrm{pH}$ decreases to 5.2 at treatment without fertilizers. It is recommended 1-2 years earlier at the joint use of organic and mineral fertilizers due to the acidifying effect of mineral fertilizers. The application of lime without fertilizers also effectively reduces the hydrolytic acidity (HAC) of the soil up to 5.3 in the year of application (the first period), up to $4.7 \mathrm{mg}$-eq. $/ 100 \mathrm{~g}$ in the fourth period. From the seventh period, when the HAC increases to a maximum value of 7.6 units in the pure liming treatment, there is a need for repeated liming. By this time, HAC reaches a higher value of 10.2 units when lime is applied with fertilizers. These findings indicate that the timing of repeated liming, determined by the $\mathrm{pH}$ and hydrolytic acidity, coincide.

Liming of leached chernozem contributes to a significant increase in the amount of exchangeable bases; when applied separately from 38-41 units to 43-44 units, when applied against the background of mineral fertilizers and manure - up to 43-45 units. As a result of the integrated application of liming, organic and mineral fertilizers designed to obtain the planned yields of rotation crops, the soil medium reaction, the amount of exchangeable bases are closely approaching the optimal parameters of leached chernozem for cultivating field crops.

Liming, both as a separate method and with applied mineral and organic fertilizers on leached chernozems in the forest-steppe zone of the Southern Urals, provides effective regulation of the physical and chemical properties of the soil which contributes to the reproduction of its fertility.

\section{Acknowledgements}

The study was carried out in the Seed-Breeding Center for Forage Crops of UFRC RAS" (project No. 075-15-2021-549).

\section{References}

1. F.Sh. Garifullin, A.Sh. Ishemiarov, Soils of the Southern Urals and their rational use, 84 (Ulianovsk, 1987) (in Russian)

2. N.I. Akanova, V.N. Temnikov, G.E. Grishin, N.A. Komarova, O.D. Shafronov, Volga Region Farmland 1, 1-3 (2011) (in Russian)

3. I.G. Asylbaiev, I.K. Khabirov, Soil Science 1, 38 (2016) DOI: $10.7868 /$ S0032180X16010020

4. I.A. Shilnikov, Chemistry in agriculture 6, 2-5 (1987) (in Russian)

5. M.E. Iakovleva Chemistry in agriculture 6, 6-8 (1987) (in Russian) 
6. DS. Orlov, Chemistry of soils, 105 (Moscow, Publishing House of Moscow State University, 1985) (in Russian)

7. M.L. Burdukovskii, V.I. Golov, I.G. Kovshik, Soil Science 10, 1248 (2016) DOI: 10.7868/S0032180X16100051

8. A.H. Sheujen, M.A. Osipov, I.A. Lebedovsky, S.V. Yesipenko, Agrochemical Bulletin 6, 2-3 (2013)

9. A.Kh. Yapparov, L.M. Bikkinina, I.A. Yapparov, Sh.A. Aliev, A.M. Yezhova, V.O. Yezhov, R.R. Gazizov, Soil Science 10, 1267-1267 (2015) DOI: 10.7868/S0032180X15100135

10. E.N. Molchanov, I.Yu. Savin, S.A. Yakovlev, D.S. Bulgakov, O.A. Makarov, Soil Science 11, 1403 (2015) DOI: 10.7868/S0032180X151 10118

11. F.Kh. Khaziev, A.Kh. Mukatanov, I.K. Khabirov, G.A. Koltsova, I.M. Gabbasova, R.Ya. Ramazanov, Soils of Bashkortostan 1, 175 (1995) 